\title{
Bleaching of Dichlorophenolindophenol by a Coupled Oxidation with Linoleate Catalyzed by Soybean Lipoxygenase
}

\author{
Christopher O. IKEDIOBI \\ Department of Chemistry, Florida Agricultural \& Mechanical University, \\ Tallahassee, Florida 32307, USA
}

Received June 20, 1977

\begin{abstract}
The coupled bleaching of 2,6-dichlorophenolindophenol by soybean lipoxygenase-1, was found to occur only under anaerobic conditions with a characteristic lag phase quite unlike the wellknown induction phase associated with lipoxygenase-catalyzed oxidation of linoleate hydroperoxide (LOOH) - free linolelic acid. The duration of this distinctive lag phase was very sensitive to lipoxygenase concentrations and equalled the length of time required for the primary enzyme activity to render the reaction solution virtually anaerobic. The onset of bleaching was marked by a gradual build-up of a ketodiene presumably derived from LOOH. Singlet $\mathrm{O}_{2}$ and superoxide anion did not appear to be involved in the enzymecatalyzed bleaching while the xanthine-xanthine oxidase system known to produce $\mathrm{O}_{2}{ }^{-}$was effective in bleaching DCPIP. It is proposed that the bleaching reaction was a result of an oxidative and irreversible alteration of DCPIP involving a number of reactive oxidants known to be produced anaerobically upon incubation of $\mathrm{LOOH}$ and linoleic acid with native lipoxygenase.
\end{abstract}

Although soybean lipoxygenase (linoleate: $\mathrm{O}_{2}$ oxidoreductase; 1.13.11.12) has been shown for some time to attack such nonsubstrate substances as carotenoids, ${ }^{1)}$ cytochrome $\mathrm{c}^{21}$ cholesterol, ${ }^{3)}$ luminol, ${ }^{4)}$ 1,3-dipenylisobenzofuran and tetraphenylcyclopentadienone ${ }^{5}$ ? during its primary activity on linoleate, very little is known about the mechanism by which this secondary action is brought about. Since 1,3-diphenylisobenzofuran and tetraphenylcyclopentadienone are good substrates for singlet $\mathrm{O}_{2}\left({ }^{1} \mathrm{O}_{2}\right)$ oxidation, ${ }^{2} \mathrm{O}_{2}$ has been suspected of being produced during lipoxygenase catalysis. ${ }^{2,5}$ DeGroot et al. ${ }^{6)}$ in their EPR spectroscopy studies on the functional role of iron in the lipoxygenase reaction, have suggested the feasibility of a superoxide radical anion $\left(\mathrm{O}_{2}^{-}\right)$generation by a reaction involving a one-electron transfer from the $\mathrm{Fe}^{2+}$ cofactor to the lipoxygenase-bound $\mathrm{O}_{2}$ which is subsequently released as $\mathrm{O}_{2}{ }^{-}$. Ikediobi and Snyder $^{7)}$ have studied the oxidation of beta-carotene by lipoxygenase and found that the linoleate hydroperoxide ( $\mathrm{LOOH}$ ) is directly involved in the oxidation process. In a recent screening of several organic dyes for their susceptibility to lipoxygenase-catalyzed bleaching, Ikediobi ${ }^{8)}$ found that 2,6-dichlorophenolindophenol (DCPIP), methylene blue and indigo carmine were easily bleached by the linoleate-lipoxygenase system. The enzymatic bleaching of DCPIP was singled out for further study in view of the widespread use of DCPIP in the titrimetric determination of ascorbic acid (vitamin C) in foodstuffs ${ }^{9)}$ and in the enzymatic estimation of hypoxanthine in stored fish ${ }^{10)}$ (a quality control measure). Evidence is presented in this paper that the coupled bleaching of DCPIP by lipoxygenase was an irreversible oxidation reaction which did not involve superoxide radical anion or singlet $\mathrm{O}_{2}$.

\section{MATERIALS AND METHODS}

Materials. The lipoxygenase used was Sigma Grade I, of specific activity 157,000 (for most of the work) or 165,000 units $\mathrm{mg}^{-1}$. These preparations were essentially pure lipoxygenase- 1 isoenzyme ${ }^{11}$ by Sephadex chromatography, electrophoresis and $\mathrm{pH}$ dependence. Bovine blood superoxide dismutase ( 3100 units $\mathrm{mg}^{-1}$ ), horse heart ferricytochrome $\mathrm{C}$, xanthine oxidase from buttermilk, beefliver catalase, xanthine and linoleic acid were purchased from the Sigma 
Chemical Company, St. Louis. $t$-Butylhydroperoxide, 2,6-dichlorophenylisobenzofuran and spectral grade acetonitrile were obtained from Fischer Scientific Company. Tetraphenylcyclopentadienone, 1,3-diphenylisobenzofuran and tetramethylethylene were products of Eastman Kodak Chemicals. Other routine chemicals were of reagent grade.

Aqueous linoleate. Assay of the primary activity of lipoxygenase was based on its oxidation of linoleate to the corresponding hydroperoxide. Aqueous linoleate was prepared daily by mixing to homogeneity $90 \mathrm{mg}$ (approx. $0.1 \mathrm{ml}$ ) of linoleic acid and $0.1 \mathrm{ml}$ of ethanol. The mixture was diluted to $33 \mathrm{ml}$ with $0.2 \mathrm{M}$ borate buffer ( $\mathrm{pH} 9$ ) and stirred gently but continuously with a magnetic stirrer to dissolve all the linoleic acid. Appropriate aliquots of the resulting solution were used for enzyme assays as described below.

Assay of lipoxygenase activity. All enzyme reactions were conducted at $25^{\circ} \mathrm{C}$. The primary activity of lipoxygenase on linoleate was assayed by measuring the increase in absorbance at $234 \mathrm{~nm}$ as a function of time using a Bausch and Lomb Spectronic 505 UVVisible spectrophotometer. The reaction was carried out in a $3 \mathrm{ml}$-quartz cuvette and a typical reaction mixture consisted of $0.5 \mathrm{ml}$ of the aqueous linoleate, $0.01 \mathrm{ml}$ of lipoxygenase-1 solution (approximately $2 \times 10^{3}$ units of activity) and $2.49 \mathrm{ml}$ of $0.2 \mathrm{M}$ sodium borate buffer ( $\mathrm{pH} \mathrm{9.0).} \mathrm{One} \mathrm{unit} \mathrm{of} \mathrm{enzyme} \mathrm{activity}$ was defined as that amount of enzyme that produced a 0.001 change in absorbance at $234 \mathrm{~nm}$ in $1 \mathrm{~min}$ at $25^{\circ} \mathrm{C}$.

Enzymatic bleaching of DCPIP. The bleaching of DCPIP by lipoxygenase was measured spectrophotometrically by recording the decrease in absorbance at $600 \mathrm{~nm}$. The $3 \mathrm{ml}$ reaction mixture consisted of $0.2 \mathrm{ml}$ of $3 \times 10^{-4} \mathrm{M}$ solution of DCPIP; $0.01 \mathrm{ml}$ of lipoxygenase solution containing $1.28 \times 10^{4}$ units of activity; $0.5 \mathrm{ml}$ of the linoleate solution and $2.29 \mathrm{ml}$ of $0.2 \mathrm{M}$ sodium borate solution ( $\mathrm{pH} 9.0$ ).

Measurement of $\mathrm{O}_{2}$ consumption. The time-course of the depletion of molecular $\mathrm{O}_{2}$ from the DCPIP. bleaching system consisting of linoleate, lipoxygenase and DCPIP was followed polarographically using the YSI Model 53 Oxygen Monitor equipped with a Clarktype sensor.

Superoxide dismutase activity. The commercial superoxide dismutase was carefully assayed by its ability to inhibit xanthine oxidase-catalyzed reduction of ferricytochrome $\mathrm{C}$ as described by McCord and Fridovich. ${ }^{12)}$

Electrolytic preparation of superoxide in acetonitrile. Pure oxygen dried by bubbling through concentrated sulfuric acid and passing through a desiccant, was reduced electrolytically to $\mathrm{O}_{2}{ }^{-}$at a mercury cathode in a three-electrode configuration with platinum as the anode and $\mathrm{Ag} / 0.1 \mathrm{M} \quad \mathrm{AgNO}_{3}$ as reference electrode. Acetonitrile was used as the solvent and tetraethylammonium perchlorate at a concentration of $0.1 \mathrm{M}$ served as the supporting electrolyte. Reduction was accomplished at a potential of $-1.1 \mathrm{~V} v s$ SCE (current level approximately $30 \mathrm{~mA}$ ). The cathode solution turned brown after the reaction had continued for about $4 \mathrm{hr}$ indicating accumulation of stable reduction product. The presence of $\mathrm{O}_{2}^{-}$was tested by chemical methods and by its superoxide dismutaseinhibitable reduction of ferricytochrome $c^{123}$

\section{RESULTS}

\section{Features of DCPIP bleaching}

When compared to carotenoid bleaching, ${ }^{1,7)}$ the bleaching of DCPIP by the linoleatelipoxygenase system showed certain distinctive features which made its study rather more interesting. Firstly, the bleaching reaction was found to take place only under anaerobic conditions as shown by a careful polarographic measurement of the $\mathrm{O}_{2}$ content of the reaction solution (Fig. 1A). Secondly, there was a definite lag phase whose duration equalled the length of time required for the primary lipoxygenase activity to render the reaction solution anaerobic, (Fig. 1B). Thirdly, the onset of bleaching appeared to coincide with maximal accumulation of $\mathrm{LOOH}$ and subsequent build-up of the $280 \mathrm{~nm}$-absorbing material (Fig. 1C).

\section{Factors affecting the kinetic lag phase}

As shown by Fig. 2 the duration of the observed lag phase was dependent on the concentration of linoleate, DCPIP and lipoxygenase, but was more sensitive to the concentration of enzyme in the reaction mixture. It was possible to abolish the lag phase by using large amounts of enzyme in the bleaching reaction. Two risks were involved in this practice: (1) lack of linearity between the initial rate of bleaching and the concentration of enzyme used (Fig. 2B) and (2) difficulty in obtaining true initial rates since the reaction was close to completion during the in- 

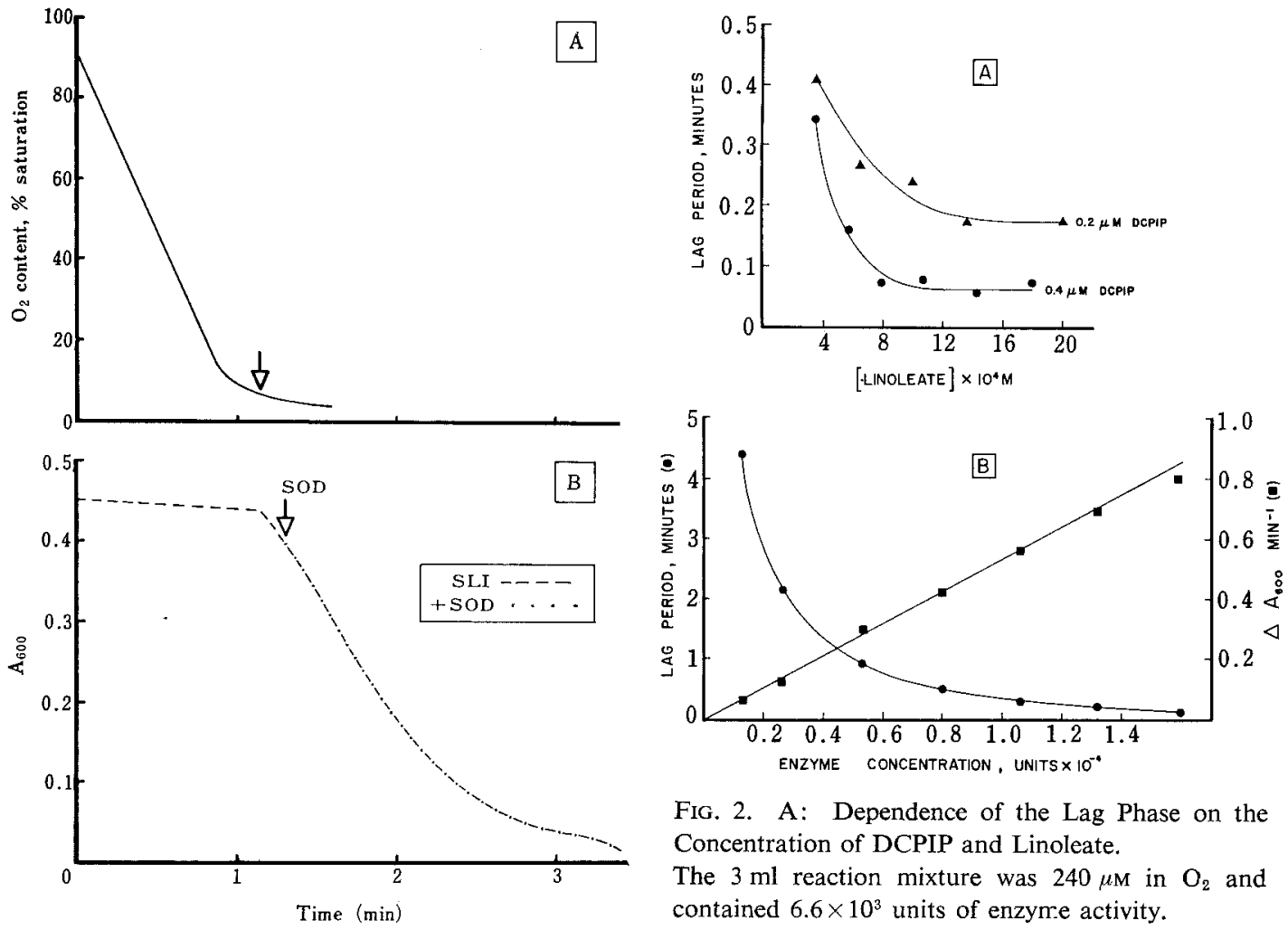

FIG. 2. A: Dependence of the Lag Phase on the Concentration of DCPIP and Linoleate.

The $3 \mathrm{ml}$ reaction mixture was $240 \mu \mathrm{M}$ in $\mathrm{O}_{2}$ and contained $6.6 \times 10^{3}$ units of enzyre activity.

B: Dependence of the Lag Phase on Enzyme Concentration and the Enzyme Concentration-initial Velocity Relationship for DCPIP Bleaching.

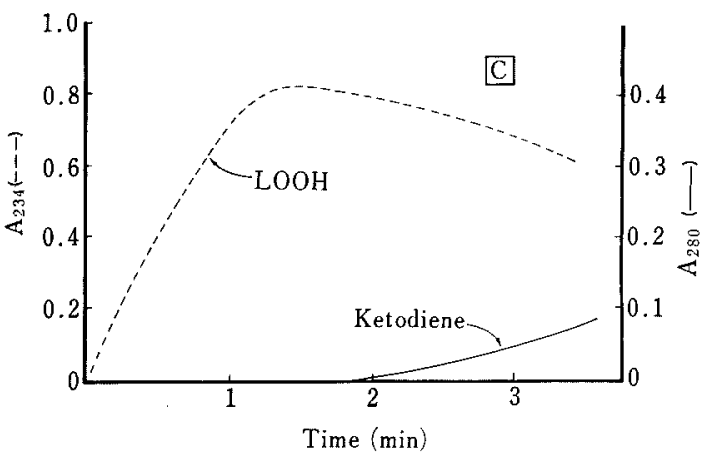

The reaction mixture $(3 \mathrm{ml})$ was $6.14 \times 10^{-4} \mathrm{M}$ in linoleate, $0.2 \mu \mathrm{M}$ in DCPIP and $240 \mu \mathrm{M}$ in $\mathrm{O}_{2}$.

terval between the addition of the enzyme to the reaction cuvette and the insertion of the latter into the spectrophotometer.

\section{Rates of DCPIP bleaching}

Varying the concentration of linoleate while keeping that of DCPIP constant at several fixed values and vice versa, influenced the

FIG. 1. Bleaching of 2,6-Dichlorophenolindophenol by the Linoleate-lipoxygenase System in a $3 \mathrm{ml}$ Reaction Mixture as Followed by a Polarographic Measurement of $\mathrm{O}_{2}$ Consumption (A), Decrease in Absorbance at $600 \mathrm{~nm}$ (B) and Increase in Absorbance at $234 \mathrm{~nm}(\mathrm{C})$ as a Function of Time.

The contents of the reaction mixture were described in the Materials and Methods.

The arrow in the polarographic trace (A) indicates the approximate onset of detectable color loss by DCPIP in the reaction solution. The arrow in B indicates the point of addition of $1.025 \times 10^{3}$ units of superoxide dismutase (SOD). initial rate of DCPIP bleaching in a manner that indicated strong substrate inhibition as shown by Fig. 3B and 3C. Furthermore it was observed that the initial rate of DCPIP bleaching decreased as the concentrtaion of the fixed substrate was increased. This is shown by the double-reciprocal plots of Fig. 3B and 3C. These results suggest that linoleic acid and DCPIP were competing for binding to the enzyme molecule. A similar competition has been observed between linoleic acid and 

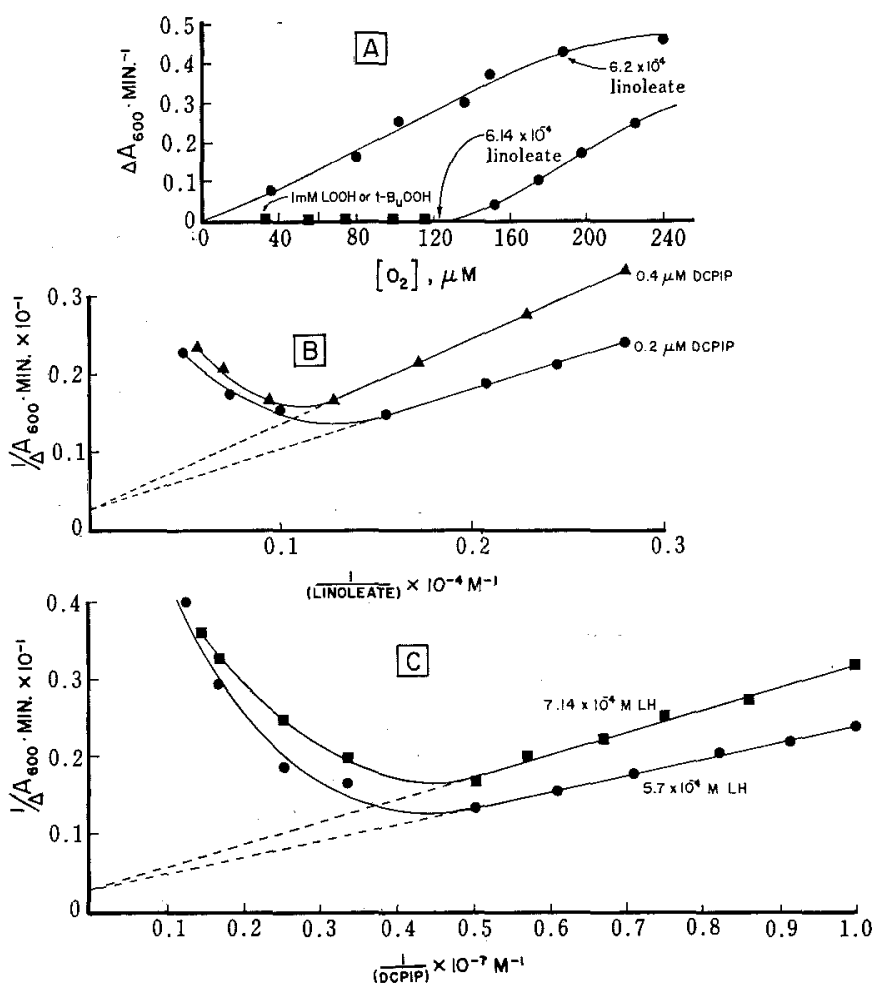

Fig. 3. A: Effect of $\mathrm{O}_{2}$ and $\mathrm{LOOH}$ (or $t-\mathrm{BuOOH}$ ) on Lipoxygenase-catalyzed Bleaching of DCPIP.

B and C: Double Reciprocal Plots of the Effects on Lipoxygenase-catalyzed DCPIP Bleaching of Varying the Linoleate and DCPIP Concentration at Different Fixed Concentrations of DCPIP and Linoleate Respectively.

betacarotene during the cooxidation of the latter by lipoxygenase. ${ }^{7}$ Substituting linoleic acid substrate with either LOOH or $t$-butylhydroperoxide $(t-\mathrm{BOOH})$ in the reaction mixture resulted in no bleaching activity as Fig. 3A clearly shows.

Bleaching by electrolytically generated $\mathrm{O}_{2}{ }^{-}$

Incubation of DCPIP with a solution of freshly generated $\mathrm{O}_{2}{ }^{-}$resulted in a significant bleaching of the dye, (Curve 1, Fig. 4A). When SOD was included in the incubation mixture, the dye was protected to some extent from the bleaching action (Curve 2, Fig. 4A). Figure 1B also shows that addition of SOD to the enzymatic bleaching system did not affect the initial rate or extent, of bleaching. Figure 5 shows that (1) the xanthine-xanthine oxidase system which is known to generate $\mathrm{O}_{2}{ }^{-}$bleached DCPIP, (2) this bleaching corresponded with oxidation of xanthine to urate (Fig. 5B) and (3) the presence of SOD did inhibit DCPIP bleaching by the xanthine oxidase reaction.

\section{Effect of singlet oxygen trap on DCPIP bleach- ing}

If singlet oxygen is produced during lipoxygenase oxidation as has been suggested in the literature, its presence might explain the seemingly nonspecific secondary activity of the enzyme. To test the involvement of ${ }^{1} \mathrm{O}_{2}$, each of the three ${ }^{1} \mathrm{O}_{2}$ scavengers-tetramethylethylene, diphenylisobenzofuran and tetraphenylcyclopentadienone-dissolved in a small volume of acetone was introduced separately into the DCPIP-bleaching system such that the final concentration of the trap in the $3 \mathrm{ml}$ 

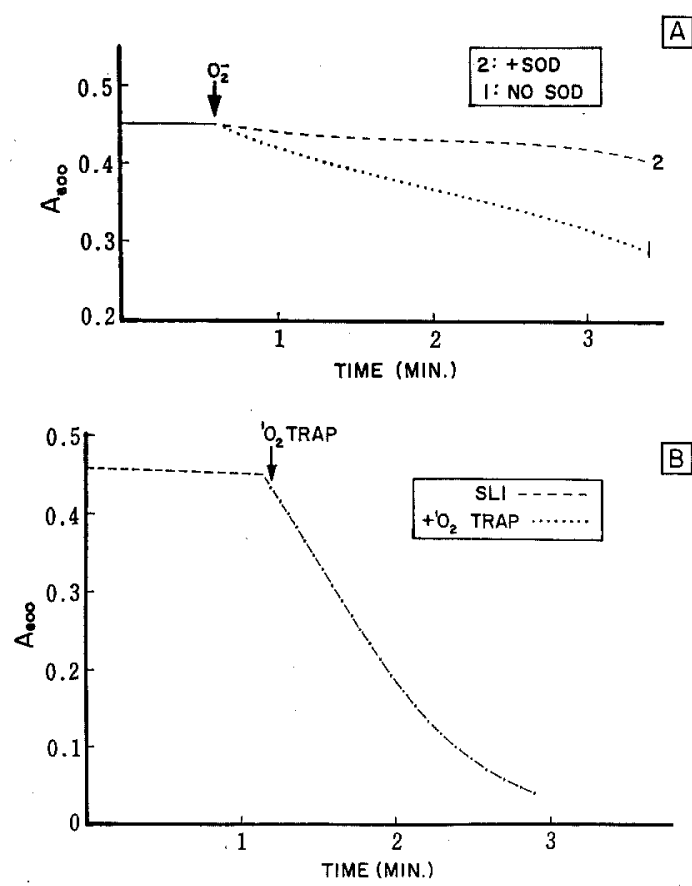

FIG. 4. A: Bleaching of DCPIP by Electrolytically Prepared Superoxide Anion and Its Inhibition by Superoxide Dismutase.

The contents of the reaction mixture were as follows: Curve 1: $0.2 \mathrm{ml}$ of $3 \times 10^{-4} \mathrm{M}$ DCPIP, $2.5 \mathrm{ml}$ of cathodic solution and $0.30 \mathrm{ml}$ of acetonitrile. Curve 2: $0.2 \mathrm{ml}$ of $3 \times 10^{-4} \mathrm{M}$ DCPIP; $2.5 \mathrm{ml}$ of cathodic solution and $3 \times 10^{3}$ units of SOD.

B: Effect of Singlet $\mathrm{O}_{2}$ Scavengers on the Lipoxygenase-Catalyzed Bleaching of DCPIP.

The arrow indicates addition of a ${ }^{1} \mathrm{O}_{2}$ trap. Three different ${ }^{1} \mathrm{O}_{2}$ traps (see RESULTs) were tested.

reaction mixture was $5 \mathrm{~mm}$. Neither the initial rate nor the extent of bleaching was affected by any of these ${ }^{1} \mathrm{O}_{2}$ scavengers (Fig. 4B).

\section{Irreversibility of DCPIP bleaching}

The fact that DCPIP bleaching occurred only under anaerobic conditions first raised the possibility that the process was a simple reduction reaction in which the conjugated double bond system of DCPIP was interrupted. Consequently one would expect the decolourisation to be reversible since DCPIP is known to be a good redox indicator. However, bubbling air or pure $\mathrm{O}_{2}$ into an
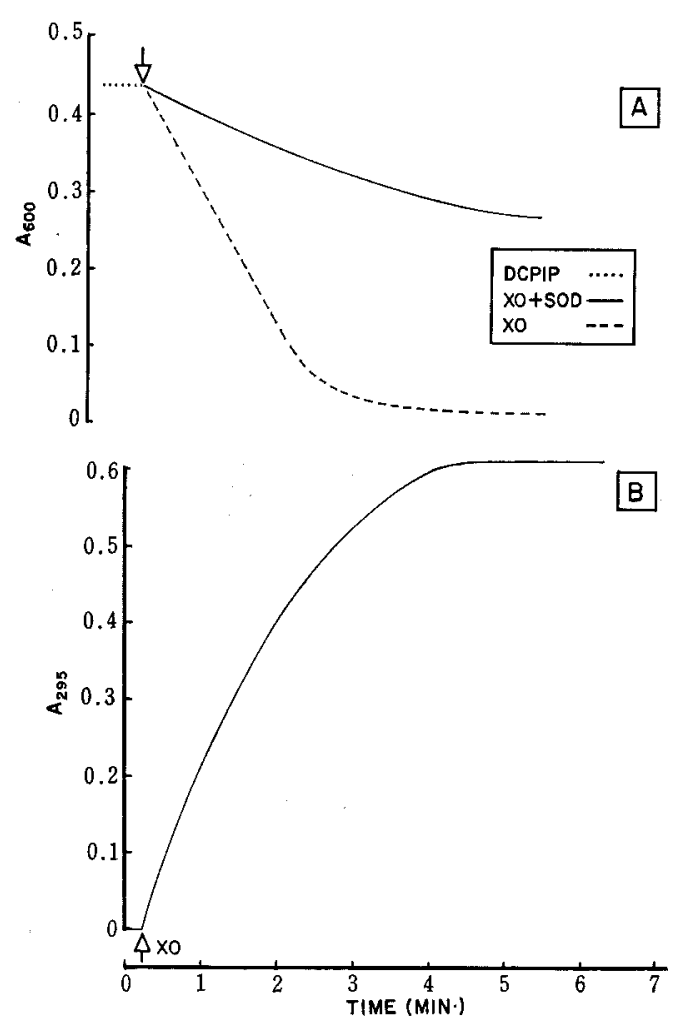

Frg. 5. Bleaching of 2,6-Dichlorophenolindophenol Coupled to the Xanthine Oxidase Reaction.

A: The progress curve represented by the dashed line was obtained with a $3 \mathrm{ml}$ reaction mixture containing: $1 \mathrm{ml}$ of $1.5 \times 10^{-3} \mathrm{M}$ xanthine solution, $0.2 \mathrm{ml}$ of $3 \times 10^{-4} \mathrm{M}$ DCPIP solution, $0.1 \mathrm{ml}$ of $3.4 \times 10^{-4} \mathrm{M}$ EDTA solution, catalase (125 ug) in $0.05 \mathrm{ml}$ of

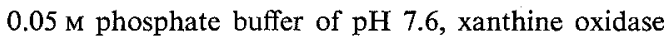
$(50 \mathrm{ug})$ in $0.05 \mathrm{ml}$ of $0.05 \mathrm{M}$ phosphate buffer of $\mathrm{pH}$ 7.6 , and $1.0 \mathrm{ml}$ of $0.05 \mathrm{M}$ phosphate buffer $\mathrm{pH} 7.6$ to bring total volume to $3 \mathrm{ml}$. The solid reaction curve was obtained with same reaction mixture in the presence of superoxide dismutase $\left(3 \times 10^{-8} \mathrm{M}\right)$ added as indicated by the arrow.

$\mathrm{B}$ : Oxidation of xanthine to uric acid by xanthine oxidase under the same reaction conditions as described above except for the absence of DCPIP.

enzymically bleached solution of DCPIP was ineffective in regenerating the blue color of the dye. At the same time, the initial rate of bleaching increased with an increase in the initial concentration of $\mathrm{O}_{2}$ in the reaction solution as depicted by Fig. 3A. 


\section{DISCUSSION}

The biphasic nature of the lipoxygenasecatalyzed bleaching of DCPIP is a phenomenon that has not been observed in any of the reported secondary activities of this enzyme. ${ }^{1 \sim 4,7,13)}$ That no significant bleaching occurred during the aerobic or lag phase suggests a definite requirement in the bleaching reaction, for either anaerobic conditions or LOOH or both. But aerobic or anaerobic incubation of DCPIP with pure LOOH and native lipoxygenase gave no bleaching until some linoleate ( $\mathrm{LH}$ ) was introduced (Fig. 3A for aerobic incubation). In contrast, betacarotene is known to undergo rapid oxidative bleaching when incubated aerobically with LOOH and lipoxygenase. ${ }^{7}$

The observed lag phase differed significantly from the well-documented induction period usually observed when lipoxygenase is incubated with LOOH-free $\mathrm{LH},{ }^{14,15}$ ) in not being abolished by the addition of catalytic amounts of exogenous LOOH. Although requiring anaerobic conditions the bleaching reaction was not a reduction since there was definite lack of reversibility (see RESULTS). Because ${ }^{1} \mathrm{O}_{2}$ and $\mathrm{O}_{2}{ }^{-}$were not detected in the enzymatic bleaching system by the usual tools, it must be concluded that these fleeting but very reactive species were not generated by the lipoxygenase system and so could not have been involved in the DCPIP bleaching. Since the xanthine oxidase (XO) reaction is known to produce $\mathrm{O}_{3}^{-}$, the bleaching of DCPIP by $\mathrm{XO}$ and its inhibition (Fig. 5A) by added SOD are attributed to $\mathrm{O}_{2}^{-}$and its SOD-catalyzed dismutation respectively:

$$
2 \mathrm{O}_{2}{ }^{-}+2 \mathrm{H}^{+} \stackrel{\text { soD }}{\longrightarrow} \mathrm{O}_{2}+\mathrm{H}_{2} \mathrm{O}_{2}
$$

This conclusion is further endorsed by the fact that electrolytically-prepared $\mathrm{O}_{2}^{-}$was effective in bleaching DCPIP and this bleaching was sensitive to SOD inhibition (Fig. 4A).

Figure 1 provides a clue to what might be going on during the anaerobic bleaching reaction. The production of linoleic acid hydroperoxide occurred during the lag phase and was limited only by the concentration of $\mathrm{O}_{2}$ in the reaction solution. The gradual decrease in the concentration of the conjugated diene chromophore (or LOOH) during the anaerobic phase was due to the formation of a ketodiene derived from $\mathrm{LOOH}$. The ketodiene chromophore is known to absorb at $280 \mathrm{~nm}$. The fact that most of the bleaching occurred during the anaerobic phase suggests a role for the accumulated LOOH (a strong oxidizing agent) and its breakdown products. It should be mentioned also that some residual $\mathrm{LH}$ was still present in the reaction mixture after the lag phase has ceased and it is conceivable that it too was involved in the bleaching. In fact this appears to be very likely based on data derived from studies of anaerobic lipoxygenase reactions. Garssen and his co-workers ${ }^{16}$ ) have shown that oxooctadecadienoic acid formation required anaerobic conditions, $\mathrm{LOOH}$, linoleic acid and lipoxygenase and that only $\mathrm{LOOH}$, not linoleic acid, was directly converted to oxooctadecadienoic acids. Other compounds shown to be derived from the $\mathrm{LOOH}$ were cleavage product(s): 13-oxo-trans-9, trans-11tridecadienoic acid, 13-oxo-cis-9, trans-11tridecadienoic acid and $n$-pentane. In further studies of the anaerobic reaction, ${ }^{17}$ ) these workers showed that oxygenated dimers resulting from reaction between one molecule of linoleic acid and one molecule of $\mathrm{LOOH}$ were also formed, thus indicating a free-radical mechanism. Free radicals were later detected in this anaerobic system by DeGroot and his co-workers. ${ }^{18)}$ It is suggested that the attack on DCPIP by these anaerobic products most of which are good oxidants could explain the rapid destruction of DCPIP under anaerobic conditions. The bleaching of DCPIP, like the cooxidation of carotenoid pigments ${ }^{1,7,13)}$ probably involved an oxidative and destructive transformation to colorless end product(s). The bleaching of DCPIP provides yet another spectrophotometric lipoxygenase assay method whose distinct advantage over other indirect assay procedures ${ }^{1,7,13,19)}$ is the absence of the need for such solubilizing 
aids as Tweens, EDTA, and acetone. Present research effort is directed at the isolation and identification of the products of DCPIP bleaching.

\section{REFERENCES}

1) H. L. Tookey, R. G. Wilson and R. L. Lohmar, J. Biol. Chem., 230, 65 (1958).

2) O. M. M. F. Oliveria, D. L. Sanioto and G. Cilento, Biochem. Biophys. Res. Commun., 58, 391 (1974).

3) J. I. Teng and L. L. Smith, J. Am. Chem. Soc., 95, 4060 (1973).

4) A. Finazzi-Agro, C. Giovagnoli, P. DeSole, L. Calabrese, G. Rotilio and B. Mondovi, FEBS Lett., 21, 183 (1972).

5) H. W-S. Chan, J. Am. Chem. Soc., 93, 2357 (1971).

6) J. J. M. C. DeGrott, G. A. Veldink, J. F. G. Vliegenhart, J. Boldingh, R. Wever and B. F. Van Gelder, Biochim. Biophys. Acta, 377, 71 (1975).
7) C. O. Ikediobi and H. E. Snyder, J. Agric. Food Chem., 25, 124 (1977).

8) C. O. Ikediobi, Fed. Proc., 35, 1629 (1975).

9) S. H. Schanderl, "Methods in Food Analysis," ed. by M. A. Josyln, Chapt. XXIV, Academic Press Inc., New York, 1970.

10) J. Spinelli, Process Biochem., 6, 36 (1971).

11) J. Christopher, E. Pistorius, and B. Axelrod, Biochim. Biophys. Acta, 284, 54 (1972).

12) J. M. McCord and I. Fridovich, J. Biol. Chem., 244, 6049 (1969).

13) H. O. Kunkel, Arch. Biochem., 30, 306 (1951).

14) J. L. Haining and B. Axelrod, J. Biol. Chem., 232, 193 (1958).

15) W. L. Smith and W. E. M. Lands, ibid., 247, 1038 (1972).

16) G. J. Garssen, J. F. G. Vliegenthard and J. Boldingh, Biochem. J., 122, 327 (1971).

17) G. J. Garssen, J. F. G. Vliegenthart and J. Boldingh, ibid., 130, 435 (1972).

18) J. J. M. C. DeGroot, G. J. Garssen, J. F. G. Vliegenthart and J. Boldingh, Biochim. Biophys. Acta, 326, 279 (1973).

19) A. Ben-Aziz, S. Grossman, I. Ascarelli and P. Budowshi, Phytochemistry, 10, 1445 (1971). 